\title{
Bias caused by water adsorption in hourly PM measurements
}

\author{
Gyula Kiss $^{1}$, Kornélia Imre ${ }^{1}$, Ágnes Molnár ${ }^{1}$, and András Gelencsér ${ }^{1,2}$ \\ ${ }^{1}$ MTA-PE Air Chemistry Research Group, University of Pannonia, Egyetem 10, 8200 Veszprém, Hungary \\ ${ }^{2}$ Department of Earth and Environmental Sciences, University of Pannonia, Egyetem 10, 8200 Veszprém, Hungary
}

Correspondence to: Gyula Kiss (kissgy@almos.uni-pannon.hu)

Received: 23 January 2017 - Discussion started: 6 March 2017

Revised: 30 May 2017 - Accepted: 11 June 2017 - Published: 13 July 2017

\begin{abstract}
Beta-attenuation monitors are used worldwide to monitor PM mass concentration with high temporal resolution. Hourly $\mathrm{PM}_{10}$ and $\mathrm{PM}_{2.5}$ dry mass concentrations are publicly available with the tacit assumption that water is effectively removed prior to the measurement. However, as both the filter material of the monitor and the aerosol particles are capable of retaining a significant amount of water even at low relative humidities, the basic assumption may not be valid, resulting in significant bias in reported $\mathrm{PM}_{10}$ and $\mathrm{PM}_{2.5}$ concentrations. Here we show that in $\mathrm{PM}_{10}$ measurement, particle-free air can produce apparent hourly average $\mathrm{PM}$ concentrations in the range of $-13-+21 \mu \mathrm{g} \mathrm{m}^{-3}$ under conditions of fluctuating relative humidity. Positive and negative apparent readings are observed with increasing and decreasing relative humidities, respectively. Similar phenomena have been observed when the instrument filter was previously loaded with atmospheric aerosol. As a result the potential measurement biases in hourly readings arising from the interaction with water may be in the range of $-53 \ldots+69 \%$.
\end{abstract}

\section{Introduction}

Air pollution has a considerable impact on quality of life and is a permanent problem in cities, leading to considerable health risk. The respirable fraction of atmospheric aerosol (particulate matter with aerodynamic diameter $<10 \mu \mathrm{m}$, $\mathrm{PM}_{10}$ ) is one of the most hazardous air pollutants. Epidemiological studies have shown that these atmospheric particles, particularly those of very small size (ultrafine particles), endanger human health by causing respiratory and cardiovascular illnesses (Natusch and Wallace, 1974; Donaldson et al., 2002; Hoek et al., 2013). In addition to their adverse health effects particulate pollution has significant impact on visibil- ity, which is an important issue for road transport, aviation, tourism and landscape protection (Hand et al., 2011; Malm et al., 2013).

The environmental legislation on ambient air quality is based on the monitoring of the mass concentration of aerosol particles sized below a specified limit $\left(\mathrm{PM}_{10}\right.$ or $\left.\mathrm{PM}_{2.5}\right)$. According to the regulation of the European Commission operative at present (Directive 2008/50/EC) the daily average concentration of $\mathrm{PM}_{10}$ should not exceed $50 \mu \mathrm{g} \mathrm{m}^{-3}$, while the upper limit for the annual average is $40 \mu \mathrm{g} \mathrm{m}^{-3}$. In case the measured concentrations exceed the alert threshold $\left(100 \mu \mathrm{g} \mathrm{m}^{-3}\right)$ special measures are implemented in order to reduce the level of pollution (smog alert), which affects the life and economic activities in the city and its surroundings. Hence knowledge on the reliability and environmental sensitivity of the measurement method used for monitoring and reporting $\mathrm{PM}_{10}$ mass concentrations is of great importance from the viewpoint of air quality legislation, health issues and the economy. As a result of multiple efforts the $\mathrm{PM}_{10}$ mass concentration has been reduced in many developed countries in the past 2 decades (Report on the Environment; European Environment Agency; Bigi and Ghermandi, 2014). However, as the $\mathrm{PM}_{10}$ mass concentrations are decreasing, the potential relative bias caused by water interactions is likely becoming more significant. This is simply due to the fact that the bias caused by adsorption or desorption of water on and from the filter medium becomes proportionally more significant relative to the aerosol mass deposited on the filter.

Water vapour is the most significant condensable species in the atmosphere that may considerably distort standard PM measurements. Adsorbed water may be partly retained on the filter and particulates even at low relative humidities (called hysteresis). The magnitude of water retention 
strongly depends on the filter material, as known for decades (Chow, 1995; Perrino et al., 2013). Tierney and Conner (1967) concluded that the effect of relative humidity (RH) on glass fibre filters was insignificant, but at $\mathrm{RH}>55 \%$ the effect on collected particulates was significant. Demuynck (1975) demonstrated that during $1 \mathrm{~h}$ high volume sampling in an urban area on a foggy day the amount of water irreversibly retained by cellulose filters is comparable to or even higher than the mass of particulate matter collected. Brown et al. (2006) compared the behaviour of quartz fibre, glass fibre and PTFE-bonded glass fibre under different RH conditions and found that the deviation in mass of certain unexposed $47 \mathrm{~mm}$ filters exceeded $450 \mu \mathrm{g}$ while the RH ranged between 30 and $81 \%$. They concluded that in terms of water uptake and mass stability, glass fibre was a more suitable filter material than quartz but the best results were obtained with PTFE-bonded glass fibre.

Although regulation is based on daily and annual average PM values, there is often need for PM data with higher temporal resolution, e.g. during air pollution episodes with high PM mass concentrations. For this reason, particulate monitors, such as the tapered element oscillating microbalance (TEOM; Patashnick and Rupprecht, 1980; Allen et al., 1997), or instruments working on the beta-attenuation principle (BAM; Macias and Husar, 1976) were developed for the continuous measurement of atmospheric particulate mass. Today these monitors have been standardized and recommended by several organizations (e.g. EPA, EMEP) and used worldwide. In many countries hourly PM data and air quality indices (AQI) are also publicly available (Air Pollution in World; Air Quality in Europe). These instruments also use filters for particle collection and are therefore subject to the same artefacts as other filter-based methods such as positive artefacts from adsorption of gaseous components on deposited particles and/or the filter media (Solomon and Sioutas, 2008). Obviously, the particulate mass collected in $1 \mathrm{~h}$ is small thus the bias caused by water may be excessive. Furthermore, the sensitivity of the particulate monitors may also limit the reliability of hourly PM data especially in less polluted environments. This may be one reason why in some countries hourly AQI are derived by the combination of hourly or 8-hourly trace gas concentrations and daily PM values (IRCELINE, DEFRA, MEP, AIRKOREA). The equivalence of the daily and annual PM data obtained with continuous particulate monitors and the $24 \mathrm{~h}$ gravimetric reference method (GRM) has been investigated in numerous studies. Chang et al. (2001) found good agreement for samples collected under moderate environmental relative humidity ( $\mathrm{RH}<70 \%)$. The ratio of the mass concentrations determined by the BAM and GRM methods was found to be $1.08 \pm 0.06$. However, with increasing RH - especially if the deliquescence $\mathrm{RH}$ of the dominant inorganic component was exceeded - the deviation between the two methods also increased, reaching 1.22 \pm 0.22 (BAM/ GRM). Salminen and Karlsson (2003) found similar results: ambient temperature below $0{ }^{\circ} \mathrm{C}$ associated with high $\mathrm{RH}$ resulted in a BAM/GRM ratio of up to 1.3. On the basis of data collected for 7 years, Takahashi et al. (2008) found that in wintertime the gravimetric method yielded higher values than the BAM while in summertime the relationship was the opposite. They suggested that the differences were likely related to the chemical composition of the aerosol particles, both inorganic salts and organic compounds. This is in agreement with other studies concluding that organic aerosol constituents affect the hygroscopicity of the aerosol particles (Gysel et al., 2004). In addition to the composition of the particulate matter the filter material may also be the reason for the discrepancy observed. In a recent study Triantafyllou et al. (2016) compared $\mathrm{PM}_{10}$ and $\mathrm{PM}_{2.5}$ data obtained with BAM and GRM using different filter materials (glass fibre, quartz fibre and Teflon) and found the best correlation when glass fibre filter was used in both measurements (glass fibre was the material of the filter tape of the beta-attenuation monitor).

PM monitors are used in long-term air quality monitoring networks as well as intensive air quality studies (e.g. the Pittsburgh air quality study, PAQS; Wittig et al., 2004). Thus, the equivalence of the monitors is also of great importance. Solomon and Sioutas (2008) summarized the continuous and semi-continuous monitoring techniques for PM mass of the US EPA PM Supersites program including standard (original) TEOM, D-TEOM and FDMS (the latter two designed to measure PM including semivolatile compounds as well) and beta-attenuation methods. In the case of the original version of the TEOMs (filters are intentionally heated to 30 or $50^{\circ} \mathrm{C}$ ), they found enhanced losses of semivolatile material from the collected particles. Grover et al. (2005) showed that in the case of $50^{\circ} \mathrm{C}$ almost all semivolatile matter was lost in the TEOM, while with D-TEOM and FDMS total $\mathrm{PM}_{2.5}$ including semivolatile compounds was measured. In betaattenuation monitors the filter is not heated directly, leading to minor loss of semivolatile compounds (Solomon and Sioutas, 2008). The study of Chung et al. (2001) provided similar results. Measurements made with a TEOM resulted in lower values than the filter-based reference measurements, while the BAM appeared to be suitable for real-time continuous $\mathrm{PM}_{2.5}$ monitoring during their study.

Hauck et al. (2004) also studied the equivalence of the gravimetric reference method (EN 12341) with the TEOM and beta-attenuation measurements at four Austrian sites and concluded that PM values measured with the TEOM and beta-attenuation monitors were not significantly different from each other. In summer the PM data measured by the monitors agreed reasonably well with those derived from the gravimetric method but in winter the monitors gave significantly lower results. In order to harmonize daily and annual PM data obtained by the TEOM, BAM and GRM, Gehrig et al. (2005) suggested a correction procedure that led to more coherent values.

The above results all indicate that under unfavourable conditions daily PM measurements can be biased significantly 
by the interaction of water with the filter material and/or the aerosol particles collected. This applies especially to hourly PM data obtained with aerosol particulate monitors, although such studies are rare (Huang and Tai, 2008) probably due to the lack of a reliable reference method to compare to. The objective of this study is to quantify potential biases in hourly readings of $\mathrm{PM}_{10}$ of standard beta-attenuation monitors caused by interaction with water.

\section{Experimental}

The investigations were carried out in a temperature controlled (at $20^{\circ} \mathrm{C}$ ) air monitoring container located at the Marczell György Observatory of the Hungarian Meteorological Service in the south-eastern part of Budapest, Hungary (GPS coordinates: $47^{\circ} 25^{\prime} 52.9^{\prime \prime} \mathrm{N}, 19^{\circ} 10^{\prime} 56.4^{\prime \prime} \mathrm{E}$ ), in July, September and November 2015. The observatory is a standard synoptic weather station where meteorological parameters, temperature and relative humidity are measured on an hourly basis. In the observatory, an urban background air pollution monitoring site is operated by the Hungarian Air Quality Network (www.levegominoseg.hu) that reports hourly $\mathrm{PM}_{10}$ mass concentration values.

A Thermo Scientific FH62C14 continuous ambient particulate monitor was used for the experiments. The instrument uses the radiometric principle of beta attenuation. Beta rays are attenuated according to an approximate exponential function of aerosol mass, while passing through deposited aerosol particles on a glass fibre filter tape. First the attenuation through the unexposed part of the filter tape is measured to correct for blank attenuation. The tape is then exposed to a constant ambient air flow maintained by a variable controlled rotary vane pump and aerosol particles are accumulated. The beta attenuation is measured again and the blank corrected attenuation is converted to mass concentrations. Additionally, the monitor measures alpha particle emissions directly from the ambient aerosol being sampled and excludes negative mass artefacts from the daughter nuclides of radon gas decay to achieve a refined mass measurement. Finally, $\mathrm{PM}_{10}$ concentration is obtained by using the corrected mass and the exact volume of sampled air.

The monitor was operated at a flow rate of $1 \mathrm{~m}^{3} \mathrm{~h}^{-1}$. In order to study the water uptake of the filter material of the PM monitor, particles were removed by replacing the $\mathrm{PM}_{10}$ inlet with a HEPA filter. Thus, only gas-phase components including water vapour were allowed to be collected on the glass fibre filter band of the instrument. Contrary to the present FH62C14 instruments the model used in this study does not incorporate a dynamic heating system designed to maintain the relative humidity of the air passing through the filter tape below a preset threshold value. Instead, this model of the monitor was equipped with a regulated sample tube heater by the manufacturer to avoid condensation of water vapour at critical sampling conditions when warm, humid air is being sampled in a cooler air-conditioned cabin. As a consequence of the inlet heating, the temperature of the air is somewhat higher in the short pathway from the entrance point of the instrument to the filter holder than it would be without heating and this results in slightly lower $\mathrm{RH}$ above the filter band. In winter the effect of inlet or internal heater is negligible as internal temperature is significantly higher than outside resulting in very low $\mathrm{RH}$ over the filter band anyway. The effect of heating the sampling inlet on water vapour adsorption/desorption was also studied by sampling with a heated (at $40^{\circ} \mathrm{C}$ ) and non-heated inlet tube.

The experiment was also repeated with a pre-loaded glass fibre filter. From 19 to 25 September 2015 the filter was first exposed to ambient air and a total of $327 \mu \mathrm{g}$ particles were collected with the ambient particulate monitor; then the $\mathrm{PM}_{10}$ inlet was replaced with a HEPA filter and sampling was continued with particle-free air and with the inlet heated at $40^{\circ} \mathrm{C}$. During the experiment the automatic filter change function was switched off.

\section{Results and discussion}

In July 2015 a sampling campaign was carried out to study the effect of inlet heating on water vapour adsorption of the filter used in the PM monitor. In this study aerosol particles were removed from the ambient air by a HEPA filter. Between 9 and 15 July the sampling system was operated without heating, while from 15 to 19 July inlet heating was set to $40{ }^{\circ} \mathrm{C}$.

The temporal variation of the apparent PM mass concentrations (measured as PM mass concentrations by the monitor) showed considerable fluctuation in the hourly average values (Fig. 1) since the incremental mass change was obviously close to the lower limit of concentration determination of the monitor. The term "the apparent PM" is used here since zero mass concentration would have been expected as particle-free air was sampled. Despite this fluctuation apparent PM mass concentrations showed a periodic diurnal variation which was even more pronounced in the $6 \mathrm{~h}$ moving averages: positive bias in the evening and at night while negative bias during daytime was observed irrespective of whether the inlet heating was on or off. Without inlet heating the magnitude of the apparent hourly average PM concentration ranged from -13 to $+21 \mu \mathrm{g} \mathrm{m}^{-3}$ and even the $6 \mathrm{~h}$ moving average concentration values varied between -7 and $+7 \mu \mathrm{g} \mathrm{m}^{-3}$ (average: $0.7 \mu \mathrm{g} \mathrm{m}^{-3}$; SD: $3.6 \mu \mathrm{g} \mathrm{m}^{-3}$ ). In the case of a heated sampling inlet the measured $6 \mathrm{~h}$ moving average apparent PM mass concentrations were generally smaller ( -4 and $+6 \mu \mathrm{g} \mathrm{m}^{-3}$; average: $0.7 \mu \mathrm{g} \mathrm{m}^{-3}$; SD: $2.2 \mu \mathrm{g} \mathrm{m}^{-3}$ ) than when a non-heated inlet was applied. This clearly indicates that a heated inlet can considerably lower this fluctuation although the temperature should be kept as low as possible in order to avoid losses of semivolatile compounds (as discussed below). 


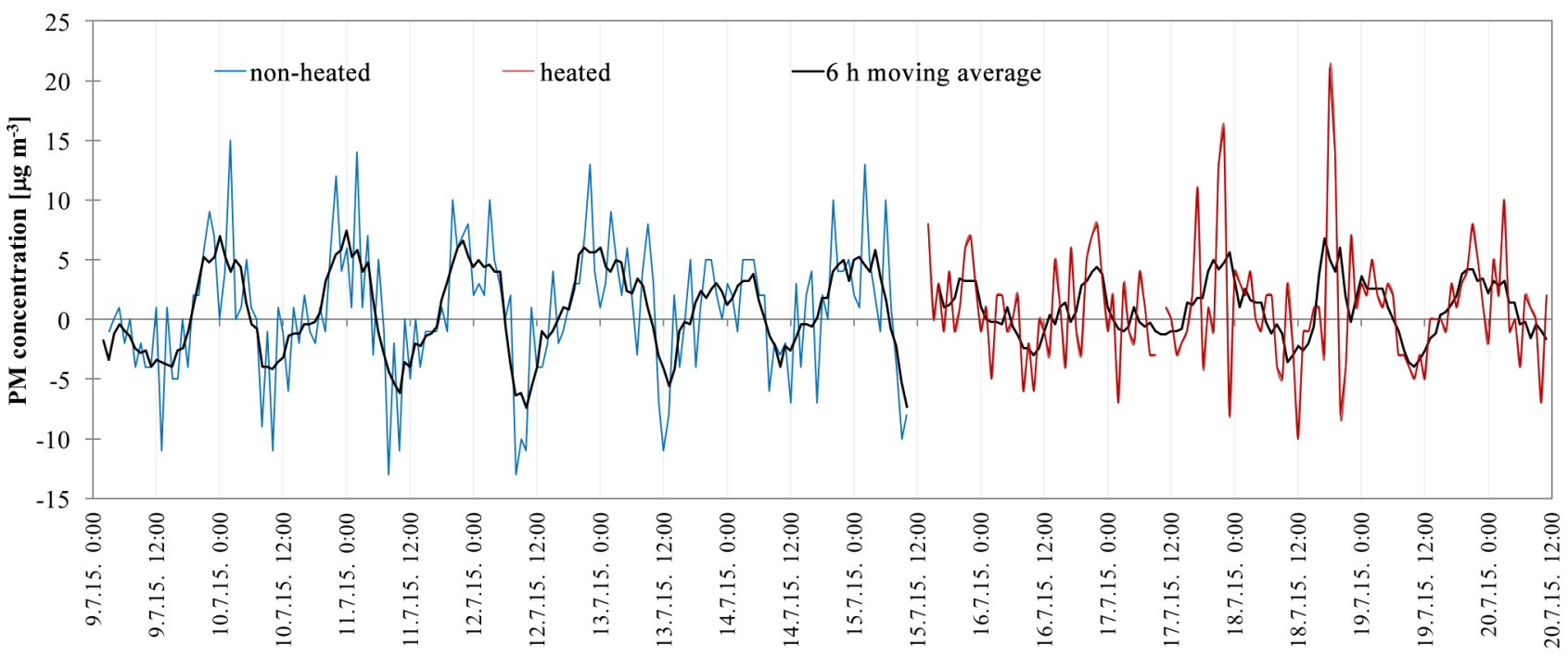

Figure 1. Temporal variation in the apparent PM mass concentration measured with particle-free air under ambient conditions in July 2015 with heated (red) and non-heated (blue) sampling inlet.
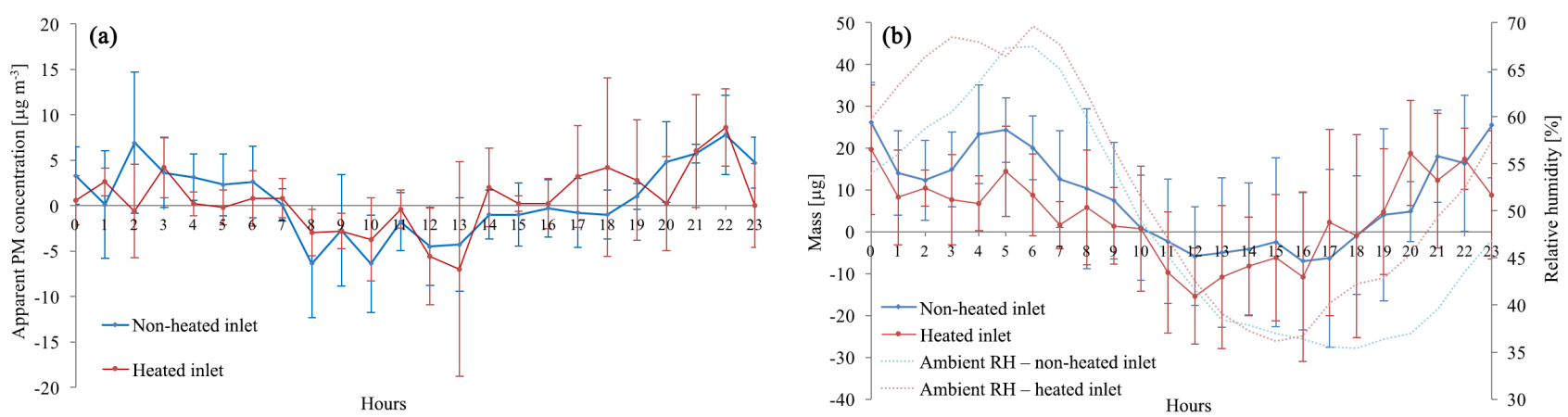

Figure 2. Daily variation of the average apparent PM mass concentration (a) and apparent net mass (b) measured by sampling particle-free air on a blank glass fibre filter in July 2015 with heated (red) and non-heated (blue) sampling inlet. The diurnal variation of ambient relative humidity is also shown (b).

In order to demonstrate diurnal variations the apparent mass concentrations measured at each hour of the days were averaged over the entire sampling period. In Fig. 2a negative apparent PM concentrations appear in the morning, while the largest positive values are found in the evening and at night. This diurnal variation of the apparent PM concentration can be explained by the operating principle of the instrument combined with interactions of water and the filter material. In Fig. $2 b$ it can be seen that the apparent net mass varied significantly during the day with a maximum around 05:00 and a minimum between 11:00 and 17:00. The measured apparent net mass is largely in phase with the daily variation of ambient RH (Fig. 2b). However, the apparent mass concentration is shifted as compared to the apparent net mass and $\mathrm{RH}$ since the instrument determines PM mass concentration as the incremental change of apparent net mass per unit air volume passed through the filter. Given the fact that particle-free air was sampled and the apparent net mass correlates with ambient relative humidity, water vapour must be the main condensable species causing positive and negative apparent PM concentrations. Additionally, water vapour is by far the most abundant condensable gas in the atmosphere (present in absolute mass concentrations of $5-17 \mathrm{~g} \mathrm{~m}^{-3}$ at $20^{\circ} \mathrm{C}$ ). It should not be ruled out that other semivolatile species (e.g. ammonium nitrate) co-condense with water and contribute to the observed apparent mass up to a few percent. The adsorption of nitric acid could also contribute to the mass change; however, at $40^{\circ} \mathrm{C}$ this compound is rather volatile (e.g. Stelson et al., 1979; Harrison and Msibi, 1994). In addition to water vapour and gaseous inorganic species volatile organic compounds may also adsorb on the filter of the PM monitor. Vecchi et al. (2009) reported as high gas-phase OC artefacts in polluted urban air of Milan, Italy, during filter sampling in summer and winter as 2.4 and $3.8 \mu^{-3} \mathrm{~m}^{-3}$, respectively. Significantly lower values were obtained in other studies. Viana et al. $(2006,2007)$ investigated the OC artefact in European 

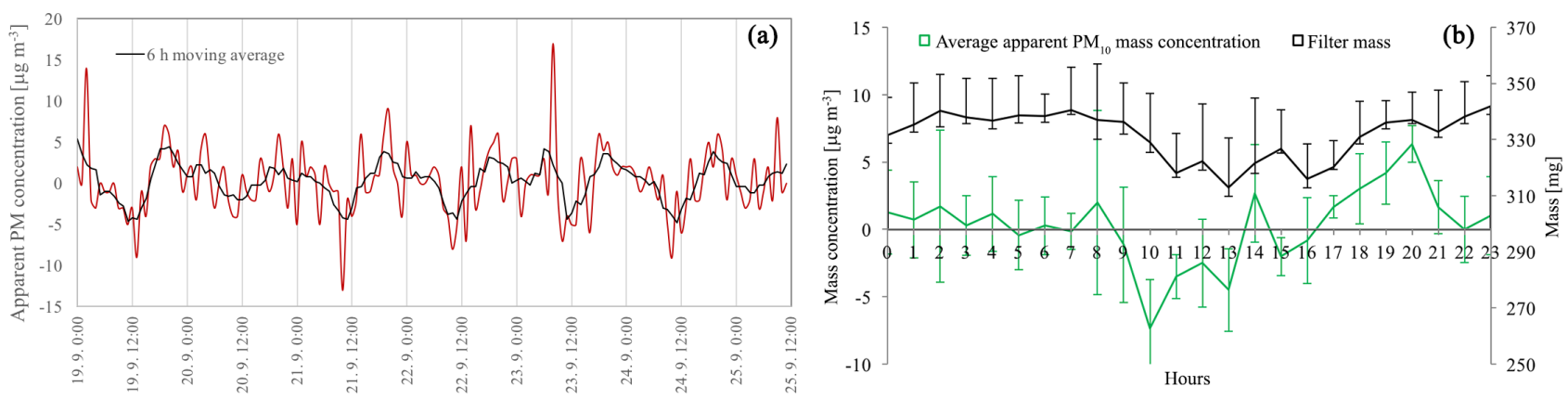

Figure 3. Temporal variation in the apparent PM mass concentration measured by sampling particle-free air on a pre-loaded glass fibre filter with the heated sampling inlet in September 2015 (a). Diurnal variation of the average apparent PM mass concentration and apparent net mass (b).

cities both in winter and summer and found it in the 0.16$0.7 \mu \mathrm{g} \mathrm{m}^{-3}$ range. However, as revealed by OC/EC analysis, the organic compounds causing the abovementioned OC artefacts evaporate from the filter only above $150^{\circ} \mathrm{C}$ (Kirchstetter at al., 2001) or even above $>310^{\circ} \mathrm{C}$ (Vecchi et al., 2009). Consequently, the fraction composed of strongly retained organic compounds cannot be the reason for the periodic mass change observed at $20^{\circ} \mathrm{C}$. It must be added that in organic artefact studies related to PM measurements the filters are analysed subsequent to the sampling and thus there is no information about potential mass change in the course of sampling.

The experiment with the blank filter and particle-free air was repeated with a heated sampling inlet in November 2015 and similar results were obtained: the $1 \mathrm{~h}$ apparent PM concentrations ranged from -11 to $+13 \mu \mathrm{g} \mathrm{m}^{-3}$ and even the $6 \mathrm{~h}$ moving average PM concentration values varied between -4 and $+4 \mu \mathrm{g} \mathrm{m}^{-3}$ (average: $0.6 \mu \mathrm{g} \mathrm{m}^{-3}$; SD: $1.8 \mu \mathrm{g} \mathrm{m}^{-3}$ ) with similar periodicity as shown above. These results clearly show that water vapour significantly biases $1 \mathrm{~h} \mathrm{PM}$ measurements in all seasons.

It should be noted, however, that the coincidence of the change in ambient RH and apparent net mass gives only an indirect evidence for the adsorption and desorption of water vapour. In order to confirm the role of water vapour an additional experiment was carried out. First, the ambient air was sucked through a dryer filled with $\mathrm{CaSO}_{4}$, then a HEPA filter and finally entered the monitor. This way both water vapour and particles were removed from the air stream and, as a consequence, the periodicity of the $6 \mathrm{~h}$ moving average disappeared and only the noise of the instrument was measured in the ca. $\pm 2 \mu \mathrm{g} \mathrm{m}^{-3}$ range.

In addition to sampling on blank filter the effect of water uptake was also studied with a filter band previously exposed to ambient aerosol. Similarly to the results of the experiments with blank filters the temporal variation of the apparent mass concentration showed considerable fluctuations but diurnal variations were also observed. The magnitude of the $1 \mathrm{~h}$ average apparent PM concentration ranged from -13 to $+17 \mu \mathrm{g} \mathrm{m}^{-3}$ and even the $6 \mathrm{~h}$ moving average concentration values varied between -5 and $+5 \mu \mathrm{g} \mathrm{m}^{-3}$ (Fig. 3a). The mass of the filter spot varied between 287 and $363 \mu \mathrm{g}$ (remember the filter spot was pre-loaded with $327 \mu$ g aerosol) during the sampling period as a consequence of adsorption and desorption of water vapour. The daily variation of apparent mass concentrations averaged over the measurement period is presented in Fig. 3b. The data show that the daily variations of both the mass concentration and the apparent net mass were similar to those measured with the blank filter (Fig. 2a and b). In the morning hours the gradual evaporation of water caused a decrease in the mass of the filter, resulting in considerable negative apparent mass concentrations (down to $-7 \mu \mathrm{g} \mathrm{m}^{-3}$ ), while in the evening the gradual condensation of water led to positive artefacts of similar magnitude.

As shown above the adsorption and desorption of atmospheric water vapour may increase and decrease, respectively, the mass of the filter, thus leading to erroneous readings of $1 \mathrm{~h}$ PM concentrations. Our experiments with particle-free air in July 2015 were run simultaneously at the same site with the monitoring of ambient $\mathrm{PM}_{10}$ concentrations by using another BAM monitor as part of the Hungarian Air Quality Network.

In the first half of the July sampling period the standard $\mathrm{PM}_{10}$ concentrations ranged from 7 to $31 \mu \mathrm{g} \mathrm{m}^{-3}$ with higher values measured during the night, at dawn or in the morning. In the second half of the period elevated PM concentrations (up to $50 \mu \mathrm{g} \mathrm{m}^{-3}$ ) were recorded, reaching the maximum on 17 July. On these days, the highest values were obtained during the night.

Large relative errors - both positive and negative - were revealed when the ratio of apparent $\mathrm{PM}$ and ambient $\mathrm{PM}_{10}$ concentrations was calculated as shown in Fig. 4. Each day of the campaign the magnitude of the relative error exceeded $38 \%$ during late evening/night when the inlet heating was switched off. In 4 out of the 6 days the relative error approached or exceeded $50 \%$ in this period of the day and the two highest values were 64 and $67 \%$. The reasons for such high relative errors are the relatively high apparent PM con- 


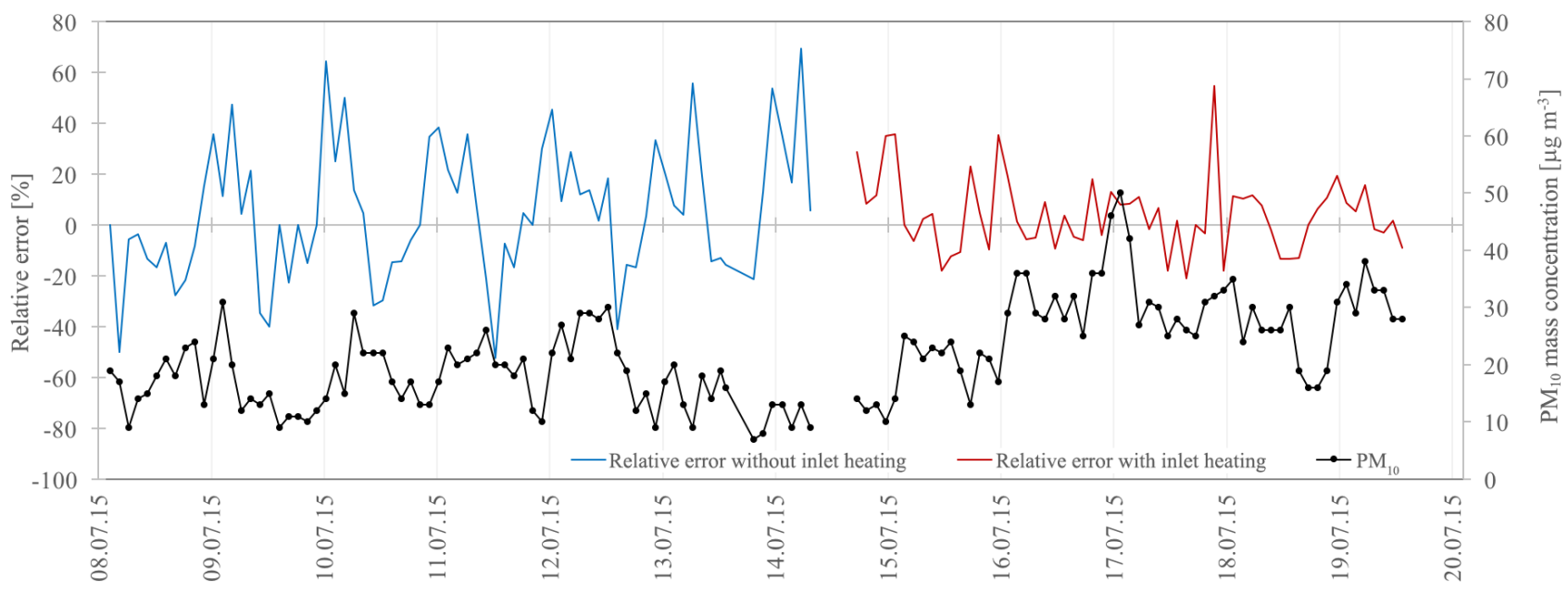

Figure 4. Relative errors in ambient hourly $\mathrm{PM}_{10}$ measurements due to the condensation or evaporation of water onto or from the glass fibre filter of the monitor. The hourly $\mathrm{PM}_{10}$ concentrations shown in this figure are the official values reported by the Hungarian Air Quality Network and measured also by a BAM monitor.

centration resulting from the condensation of water vapour and the low ambient $\mathrm{PM}_{10}$ concentrations at this time of day (often between 9 and $15 \mu \mathrm{g} \mathrm{m}^{-3}$ ). Heating of the inlet tube to $40^{\circ} \mathrm{C}$ decreased the magnitude of the error considerably but still relative errors exceeding $35 \%$ were observed occasionally. It should also be noted that the decrease of relative error experienced with a heated sampling inlet can be attributed partly to higher ambient $\mathrm{PM}_{10}$ concentrations that occurred during the second half of the campaign.

In contrast to the above observations negative relative errors were found during the morning hours although their magnitude (21-53\%) was somewhat lower than during the night. The highest negative values were observed around 10:00 as a consequence of fast evaporation of previously condensed water vapour. The lower relative errors can be explained by the higher ambient $\mathrm{PM}_{10}$ concentrations in this period of the day $\left(15-22 \mu \mathrm{g} \mathrm{m}^{-3}\right)$. Similarly to the positive relative errors observed during the night the heating of the inlet tube decreased the magnitude of the negative relative errors as well but this can be partially attributed to the elevated ambient PM concentrations in the second half of the campaign.

\section{Conclusions}

Adsorption and desorption of water vapour under periodically changing ambient relative humidities cause considerable diurnal variation in the mass of the filter band of the beta-attenuation monitor. This leads to positive and negative apparent PM concentrations even if particle-free air is sampled. In the evening hours - when adsorption of water vapour occurs due to the increasing ambient $\mathrm{RH}$ even inside the monitor - the increased apparent net mass resulted in positive apparent concentrations, while in the morning - when water is desorbed due to decreasing ambient $\mathrm{RH}$ - negative apparent concentrations were measured. This phenomenon was observed with an empty glass fibre filter but deviations of similar magnitude were also found with a filter previously loaded with ambient aerosol. Heating of the sampling inlet at $40^{\circ} \mathrm{C}$ reduces but cannot completely eliminate this artefact related to water vapour adsorption/desorption. This artefact can severely bias $1 \mathrm{~h}$ ambient $\mathrm{PM}_{10}$ measurements in either direction. This was studied by comparing apparent PM concentrations to ambient $\mathrm{PM}_{10}$ concentrations measured simultaneously. Positive relative errors of 38-69\% were observed during the night when ambient $\mathrm{PM}_{10}$ concentrations were low $\left(9-15 \mu \mathrm{g} \mathrm{m}^{-3}\right)$. In contrast, in the morning negative relative errors of $21-53 \%$ were measured. The smaller negative relative errors can be explained by the gradual release of water from the filter material as well as the generally higher $\mathrm{PM}_{10}$ concentrations in this period of the day (15$22 \mu \mathrm{g} \mathrm{m}^{-3}$ ).

These results clearly show that $1 \mathrm{~h} \mathrm{PM}_{10}$ concentrations should be used with extreme caution since significant measurement bias may occur at low ambient $\mathrm{PM}_{10}$ concentrations as a consequence of water vapour adsorption on or desorption from the filter material of the beta-attenuation monitor. In contrast, at high ambient $\mathrm{PM}_{10}$ concentrations water vapour uptake and release by the collected aerosol particles may also bias the reported $1 \mathrm{~h} \mathrm{PM}_{10}$ data. The effect of water vapour adsorption/desorption is even more pronounced when $\mathrm{PM}_{2.5}$ or $\mathrm{PM}_{1}$ concentrations are to be determined. In addition to water vapour, organic and inorganic trace gases might also contribute to the mass change of the filter and thus increase the magnitude of the bias. Measurements with lower time resolution (e.g. $24 \mathrm{~h}$ ) are likely much less affected since much larger particle mass is collected and the change in am- 
bient relative humidity is generally much less pronounced at the very same hour of the day from one day to another.

Data availability. All the data used and produced for the purposes of this paper are freely available and can be requested from the corresponding author.

Competing interests. The authors declare that they have no conflict of interest.

Acknowledgements. The financial support of the National Research, Development and Innovation Office - NKFIH 113059 project and the technical assistance of Ádám Tóth are gratefully acknowledged. We thank the Hungarian Air Quality Monitoring Network for the technical support and the data availability.

Edited by: Pierre Herckes

Reviewed by: three anonymous referees

\section{References}

AIRKOREA: available at: https://www.airkorea.or.kr/eng/cai/cai1, last access: 11 July 2017.

Air Pollution in World: real-time air quality index visual map, available at: http://aqicn.org/map/world/\#@g/47.551/18.9621/7z, last access: 11 July 2017.

Air Quality in Europe: available at: http://www.airqualitynow.eu/, last access: 11 July 2017.

Allen, G., Sioutas, C., Koutrakis, P., Reiss, R., Lurmann, F. W., and Roberts, P. T.: Evaluation of the TEOM(R) method for measurement of ambient particulate mass in urban areas, J. Air Waste Manage., 47, 682-689, https://doi.org/10.1080/10473289.1997.10463923, 1997.

Bigi, A. and Ghermandi, G.: Long-term trend and variability of atmospheric $\mathrm{PM}_{10}$ concentration in the Po Valley, Atmos. Chem. Phys., 14, 4895-4907, https://doi.org/10.5194/acp-144895-2014, 2014.

Brown, A. S., Yardley, R. E., Quincey, P. G., and Butterfield, D. M.: Studies of the effect of humidity and other factors on some different filter materials used for gravimetric measurements of ambient particulate matter, Atmos. Environ., 40, 4670-4678, https://doi.org/10.1016/j.atmosenv.2006.04.028, 2006.

Chang, C. T., Tsai, C. J., Lee, C. T., Chang, S. Y., Cheng, M. T., and Chein, H. M.: Differences in $\mathrm{PM}_{10}$ concentrations measured by beta-gauge monitor and hi-vol sampler, Atmos. Environ., 35, 5741-5748, 2001.

Chow, J. C.: Measurement methods to determine compliance with ambient air quality standards for suspended particles, J. Air Waste Manage., 45, 320-382 1995.

Chung, A., Chang, D. P. Y., Kleeman, M. J., Perry, K. D., Cahill, T. A., Dutcher, D., McDougall, E. M., and Stroud, K.: Comparison of real-time instruments used to monitor airborne particulate matter, J. Air Waste Manage., 51, 109-120, https://doi.org/10.1080/10473289.2001.10464254, 2001.
DEFRA: available at: https://uk-air.defra.gov.uk/air-pollution/daqi? view=more-info\&pollutant=pm10\#pollutant, last access: 11 July 2017.

Demuynck, M.: Determination of irreversible absorption of water by cellulose filters, Atmos. Environ., 9, 523-528, https://doi.org/10.1016/0004-6981(75)90113-4, 1975.

Directive 2008/50/EC of the European Parliament and of the Council of 21 May 2008 on ambient air quality and cleaner air for Europe: OJ L 152, 11 June 2008, 1-44, 2008 http://eur-lex. europa.eu/legal-content/en/ALL/?uri=CELEX:32008L0050, last access: 11 July 2017.

Donaldson, G., Seemungal, T., Bhowmik, A., and Wedzicha, J.: Relationship between exacerbation frequency and lung function decline in chronic obstructive pulmonary disease, Thorax, 57, 847852, https://doi.org/10.1136/thorax.57.10.847, 2002.

European Environment Agency: Trends in $\mathrm{PM}_{10}$ and $\mathrm{PM}_{2.5}$ annual concentrations per station type, available at: https://www.eea.europa.eu/data-and-maps/daviz/ trends-in-pm10-top-and\#tab-dashboard-01, last access: 11 July 2017.

Gehrig, R., Hueglin, C., Schwarzenbach, B., Seitz, T., and Buchmann, B.: A new method to link $\mathrm{PM}_{10}$ concentrations from automatic monitors to the manual gravimetric reference method according to EN12341, Atmos. Environ., 39, 2213-2223, https://doi.org/10.1016/j.atmosenv.2005.01.005, 2005.

Grover, B. D., Kleinman, M., Eatough, N. L., Eatough, D. J., Hopke, P. K., Long, R. W., Wilson, W. E., Meyer, M. B., and Ambs, J. L.: Measurement of total $\mathrm{PM}_{2.5}$ mass (nonvolatile plus semi-volatile) with the filter dynamic measurement system tapered element oscillating microbalance monitor, J. Geophys. Res., 110, D07S03, https://doi.org/10.1029/2004JD004995, 2005.

Gysel, M., Weingartner, E., Nyeki, S., Paulsen, D., Baltensperger, U., Galambos, I., and Kiss, G.: Hygroscopic properties of water-soluble matter and humic-like organics in atmospheric fine aerosol, Atmos. Chem. Phys., 4, 35-50, https://doi.org/10.5194/acp-4-35-2004, 2004.

Hand, J. L., Copeland, S. A., Day, D. E., Dillner, A. M., Indresand, H., Malm, W. C., McDade, C. E., Moore, C. T. Jr., Pitchford, M. L., Schichtel, B. A., and Watson, J. G.: Spatial and seasonal patterns and temporal variability of haze and its constituents in the United States, Report V: June 2011, IMPROVE report, Cooperative Institute for Research in the Atmosphere, Colorado State University, Fort Collins, USA, 2011.

Hauck, H., Berner, A., Gomisceka, B., Stoppera, S., Puxbaum, H., Kundi, M., and Preining, O.: On the equivalence of gravimetric PM data with TEOM and betaattenuation measurements, Aerosol Science, 35, 1135-1149, https://doi.org/10.1016/j.jaerosci.2004.04.004, 2004.

Harrison, R. M. and Msibi, M. I.: Validation of techniques for fast response measurement of $\mathrm{HNO}_{3}$ and $\mathrm{NH}_{3}$ and determination of the $\left[\mathrm{NH}_{3}\right]\left[\mathrm{HNO}_{3}\right]$ concentration product, Atmos. Environ., 28, 247-255, https://doi.org/10.1016/1352-2310(94)90099-X, 1994

Hoek, G., Krishnan, R. M., Beelen, R., Peters, A., Ostro, B., Brunekreef, B., and Kaufman, J. D.: Long-term air pollution exposure and cardio-respiratory mortality: a review, Environ. Health, 12, 43, https://doi.org/10.1186/1476-069X-12-43, 2013.

Huang, C. H. and Tai, C. Y.: Relative humidity effect on $\mathrm{PM}_{2.5}$ readings recorded by collocated beta atten- 
uation monitors, Environ. Eng. Sci., 25, 1079-1089, https://doi.org/10.1089/ees.2007.0142, 2008.

IRCELINE: available at: http://www.irceline.be/en/air-quality/ measurements/air-quality-index/information, last access: 11 July 2017.

Kirchstetter, T. W., Corrigan, C. E., and Novakov, T.: Laboratory and field investigation of the adsorption of gaseous organic compounds onto quartz filters, Atmos. Environ., 35, 1663-1671, 2001.

Macias, E. S. and Husar, R. B.: Atmospheric particulate mass measurement with beta attenuation mass monitor, Environ. Sci. Technol., 10, 904-907, 1976.

Malm, W. C., Schichtel, B. A., Barna, M. G., Gebhart, K. A., Rodriguez, M. A., Collett Jr., J. L., Carrico, C. M., Benedict, K. B., Prenni, A. J., and Kreidenweis, S. M.: Aerosol species concentrations and source apportionment of ammonia at Rocky Mountain National Park, J. Air Waste Manage., 63, 1245-1263, https://doi.org/10.1080/10962247.2013.804466, 2013.

MEP, People's Republic of China Ministry of Environmental Protection Standard: Technical Regulation on Ambient Air Quality Index (Chinese PDF), http://datacenter.mep.gov.cn/index!environmentAirHourDetail. action?cityName=\%E9\%82\%A2\% E5\%8F\%B0\%E5\%B8\%82, last access: 11 July 2017.

Natusch, D. F. S. and Wallace, J. R.: Urban aerosol toxicity: the influence of particle size, Science, 186, 695-699, 1974.

Patashnick, H. and Rupprecht, G.: New real-time monitoring instrument for suspended particulate mass concentration - TEOM, Abstract of papers of the American Chemical Society, Div. Pet. Chem., 25; Conference: 179. national meeting of the American Chemical Society, Houston, 1980.

Perrino, C., Canepari, S., and Catrambone, M.: Comparing the performance of teflon and quartz membrane filters collecting atmospheric PM: influence of atmospheric water, Aerosol Air Qual. Res., 13, 137-147, https://doi.org/10.4209/aaqr.2012.07.0167, 2013.

Report on the Environment: Particulate matter concentrations, available at: https://cfpub.epa.gov/roe/indicator_pdf.cfm?i=9, last access: 11 July 2017.

Salminen, K. and Karlsson, V.: Comparability of low-volume $\mathrm{PM}_{10}$ sampler with beta-attenuation monitor in background air, Atmos. Environ., 37, 3707-3712, 2003.
Solomon, P. A. and Sioutas, C.: Continuous and semicontinuous monitoring techniques for particulate matter mass and chemical components: a synthesis of findings from EPA's particulate matter supersites program and related studies, J. Air Waste Manage., 58, 164-195, https://doi.org/10.3155/1047-3289.58.2.164, 2008.

Stelson, A. W., Friedlander, S. K., and Seinfeld, J. H.: A note on the equilibrium relationship between ammonia and nitric acid and particulate ammonium nitrate, Atmos. Environ., 13, 369-371, 1979.

Takahashi, K., Minoura, H., and Sakamato, K.: Examination of discrepancies between beta-attenuation and gravimetric methods for the monitoring of particulate matter, Atmos. Environ., 42, 52325240, 2008.

Tierney, G. P. and Conner, W. D.: Hygroscopic effects on weight determinations of particulates collected on glass-fiber filters, Am. Ind. Hyg. Assoc J., 28, 363-365, https://doi.org/10.1080/00028896709342537, 1967.

Triantafyllou, E., Diapouli, E., Tsilibari, E. M., Adamopoulos, A. D., Biskos, G., and Eleftheriadis, K.: Assessment of factors influencing PM mass concentration measured by gravimetric $\&$ beta attenuation techniques at a suburban site, Atmos. Environ., 131, 409-417, 2016.

Vecchi, R., Valli, G., Fermo, P., D’Alessandro, A., Piazzalunga, A., and Bernardoni, V.: Organic and inorganic sampling artefacts assessment, Atmos. Environ., 43, 1713-1720, 2009.

Viana, M., Chi, X., Maenhaut, W., Cafmeyer, J., Querol, X., Alastuey, A., Mikuška, P., and Večeřa, Z.: Influence of sampling artefacts on measured PM, OC, and EC levels in carbonaceous aerosols in an urban area, Aerosol Sci. Tech., 40, 107-117, https://doi.org/10.1080/02786820500484388, 2006.

Viana, M., Maenhaut, W., ten Brink, H. M., Chi, X., Weijers, E., Querol, X., Alastuey, A., Mikuška, P., and Večeřa, Z.: Comparative analysis of organic and elemental carbon concentrations in carbonaceous aerosols in three European cities, Atmos. Environ., 41, 5972-5983, 2007.

Wittig, A. E., Anderson, N., Khlystov, A. Y., Pandis, S. N., Davidson, C. I., and Robinson, A. L.: Pittsburgh air quality study overview, Atmos. Environ., 38, 3107-3125, 2004. 